\title{
Postprandial plasma betaine and other methyl donor-related responses after consumption of minimally processed wheat bran or wheat aleurone, or wheat aleurone incorporated into bread
}

\author{
Edel M. Keaveney ${ }^{1}$, Ruth K. Price ${ }^{1}$, Lesley L. Hamill ${ }^{1}$, Julie M. W. Wallace ${ }^{1}$, Helene McNulty ${ }^{1}$, \\ Mary Ward ${ }^{1}$, J. J. Strain ${ }^{1}$, Per M. Ueland ${ }^{2,3}$, Anne M. Molloy ${ }^{4}$, Vieno Piironen ${ }^{5}$, Walter von Reding ${ }^{6}$, \\ Peter R. Shewry ${ }^{7}$, Jane L. Ward ${ }^{7}$ and Robert W. Welch ${ }^{1 *}$ \\ ${ }^{1}$ Northern Ireland Centre for Food and Health, University of Ulster, Coleraine, UK \\ ${ }^{2}$ Department of Clinical Science, University of Bergen, Bergen, Norway \\ ${ }^{3}$ Laboratory of Clinical Biochemistry, Haukeland University Hospital, Bergen, Norway \\ ${ }^{4}$ Department of Clinical Medicine, Trinity College Dublin, Dublin, Ireland \\ ${ }^{5}$ Department of Food and Environmental Sciences, University of Helsinki, Finland \\ ${ }^{6}$ Bübler AG, CH-9240 Uzwil, Switzerland \\ ${ }^{7}$ Rothamsted Research, Harpenden, UK
}

(Submitted 28 April 2014 - Final revision received 16 September 2014 - Accepted 22 October 2014 - First published online 13 January 2015)

\section{Abstract}

The bran and particularly the aleurone fraction of wheat are high in betaine and other physiological methyl donors, which may exert beneficial physiological effects. We conducted two randomised, controlled, cross-over postprandial studies to assess and compare plasma betaine and other methyl donor-related responses following the consumption of minimally processed bran and aleurone fractions (study A) and aleurone bread (study B). For both studies, standard pharmacokinetic parameters were derived for betaine, choline, folate, dimethylglycine (DMG), total homocysteine and methionine from plasma samples taken at $0,0 \cdot 5,1,2$ and $3 \mathrm{~h}$. In study A ( $n$ 14), plasma betaine concentrations were significantly and substantially elevated from 0.5 to $3 \mathrm{~h}$ following the consumption of both bran and aleurone compared with the control; however, aleurone gave significantly higher responses than bran. Small, but significant, increases were also observed in DMG measures; however, no significant responses were observed in other analytes. In study $\mathrm{B}$ ( $n$ 13), plasma betaine concentrations were significantly and substantially higher following consumption of the aleurone bread compared with the control bread; small, but significant, increases were also observed in DMG and folate measures in response to consumption of the aleurone bread; however, no significant responses were observed in other analytes. Peak plasma betaine concentrations, which were $1 \cdot 7-1 \cdot 8$ times the baseline levels, were attained earlier following the consumption of minimally processed aleurone compared with the aleurone bread (time taken to reach peak concentration $1 \cdot 2 v \cdot 2 \cdot 1 \mathrm{~h}$ ). These results showed that the consumption of minimally processed wheat bran, and particularly the aleurone fraction, yielded substantial postprandial increases in plasma betaine concentrations. Furthermore, these effects appear to be maintained when aleurone was incorporated into bread.

Key words: Betaine: Methyl donors: Wheat aleurone: Wheat bran

Wheat grain is milled commercially to produce refined white flour using processes that separate the starchy endosperm from the outer bran fraction. The bran, which accounts for $15-16 \%$ of the whole grain, is much higher in minerals, vitamins and other potentially bioactive components than whole-grain wheat ${ }^{(1)}$. Furthermore, these components, which include folate, choline and betaine, are concentrated in the aleurone layer. Aleurone is a metabolically active cell layer that, botanically, is part of the endosperm, but which comprises $45-50 \%$ of the bran produced in commercial milling ${ }^{(1-6)}$. Folate, choline and betaine are physiological methyl donors, which play important roles in one-carbon metabolism ${ }^{(7-9)}$ and DNA methylation ${ }^{(7)}$. Furthermore, betaine is an osmolyte and can act as a lipotrope (preventing or reducing fat accumulation

Abbreviations: $\mathrm{AUC}_{\mathrm{corr}}$, baseline-corrected AUC; $C_{\max , \mathrm{corr}}$, baseline-corrected peak concentration; DMG, dimethylglycine; tHcy, total homocysteine; $t_{\text {max }}$, time taken to reach peak concentration.

*Corresponding author: R. W. Welch, fax + 44287012 3023, email rw.welch@ulster.ac.uk

w Deceased 7 February 2012 
in the liver) ${ }^{(10)}$, while choline is involved in neurotransmission and lipid cholesterol transport ${ }^{(8)}$, and folate is necessary for DNA synthesis ${ }^{(11)}$.

Folate, choline and betaine in whole-grain wheat products may be factors contributing to the decreased risks of chronic diseases associated with high intakes of whole grain, which have been observed in epidemiological studies ${ }^{(12-14)}$. Furthermore, two large prospective studies have found inverse associations between not only whole grain intake but also bran intake and the incidence of heart diseases in men ${ }^{(15)}$ and women ${ }^{(16)}$. The components and mechanisms by which whole grains confer this protection are not fully understood $^{(17)}$, and whole-grain intervention studies have yielded equivocal results ${ }^{(18)}$. However, a 4 -week intervention with aleurone-rich foods by our group ${ }^{(19)}$ and a 2-week intervention with whole-grain foods by Ross \& Bruce $^{(20)}$ have resulted in increased intakes and plasma concentrations of betaine that were associated with improvements in a number of biomarkers of health, including decreased plasma total homocysteine (tHcy) and LDL-cholesterol concentrations. These studies have suggested that betaine and the other methyl donors, folate and choline, may play roles in the health benefits of wheat-based whole-grain foods.

Previous postprandial studies with human subjects have demonstrated the uptake of folate from a cereal made from aleurone flour ${ }^{(2)}$ and of betaine from a mixed meal that included wheat bran ${ }^{(21)}$. However, to date, no studies have assessed postprandial plasma betaine, folate and choline responses following the consumption of wheat bran or aleurone fractions, or aleurone incorporated into a bread product. Thus, we conducted two randomised, controlled, human postprandial studies. The primary aims were to evaluate and compare postprandial plasma betaine and other methyl donor-related responses following the consumption of $50 \mathrm{~g}$ portions of wheat bran or wheat aleurone that were minimally processed by adding sugar, mixing with water and boiling (study A), and $50 \mathrm{~g}$ portions of wheat aleurone that were incorporated into a traditional Irish, yeast-free bread (study B).

\section{Experimental methods}

\section{Participants}

For each study, a separate group of fourteen healthy participants (seven males and seven females) were recruited by advertisements at the University of Ulster, Coleraine. The participants met the following inclusion criteria: age $\geq 18$ and $\leq 40$ years; $\mathrm{BMI} \geq 18$ and $\leq 35 \mathrm{~kg} / \mathrm{m}^{2}$; non-smokers; consuming a normal mixed diet; not intolerant to wheat or gluten; not pregnant or lactating; no chronic diseases; not taking any prescribed medication or supplements. These studies were conducted according to the guidelines laid down in the Declaration of Helsinki, and all procedures involving human participants were approved by the Research Ethical Committee of the University of Ulster. Written informed consent was obtained from all the participants. These trials were registered at http://www.controlled-trials.com as ISRCTN09560399 and ISRCTN27269236.

\section{Study design and treatments}

Both postprandial studies used a participant-blinded, withinparticipant, cross-over design with a 1-week washout between each test day. Uptake of phenolics from the treatments was assessed as part of a wider project; thus, the participants were asked to avoid foods with high phenolic content (i.e. whole grains, fruit, vegetables, sauces, chocolate, tea, coffee, fruit juices, beer and red wine) for $2 \mathrm{~d}$ before each test day. Within-participant standardised selections of foods with low phenolic content (i.e. refined grain products, meat, fish and dairy products) were provided.

On each test day, the participants attended the University of Ulster, Coleraine, between 08.00 and 09.00 hours, having fasted from 22.00 hours the previous night. On arrival, baseline blood samples were taken and the participants were asked to consume the treatments within $15 \mathrm{~min}$. In study $\mathrm{A}$, treatments were (1) minimally processed wheat bran $(50 \mathrm{~g})$, (2) minimally processed wheat aleurone (50g) and (3) control. In study B, treatments were (1) aleurone bread (50 g wheat aleurone incorporated into bread) and (2) control bread, based on white wheat flour. The participants were provided with uncarbonated bottled water for consumption during the postprandial sampling period. Compliance to the treatments was assessed directly by weighing residues.

To improve palatability, sugar was offered with the treatments in study A, and butter was offered with the treatments in study B. Discretionary intakes of sugar and butter, which ranged from 0 to $25 \mathrm{~g}$ and 0 to $40 \mathrm{~g}$, respectively, were standardised within the participants across the test days.

\section{Preparation and analysis of the treatments}

The bran and aleurone fractions that were produced by dry milling from the hard white winter wheat cultivar Tiger (Triticum aestivum L.) were supplied by Bühler AG, Uzwil, Switzerland, and had the following composition (g/100 g), respectively: DM, 86.7, 90.0; fibre, 54.0, 46.9; protein, 13.2, 17.8; carbohydrate, $11 \cdot 5,11 \cdot 1$; ash, $6 \cdot 1,10 \cdot 2$; fat, $2 \cdot 9$, $4 \cdot 1$.

The treatments were batch prepared and formulated to balance macronutrient and fibre contents using refined wheat fibre, wheat starch, wheat protein and vegetable fat, and composition data from the suppliers (Table 1). The bran and aleurone fractions were minimally processed by bulk-mixing dry ingredients, adding water, blending, boiling (10 min), portioning and storing $\left(-18^{\circ} \mathrm{C}\right)$. The breads were prepared using a traditional Irish, yeast-free, soda bread recipe, with sodium bicarbonate as the leavening agent, where the ingredients were mixed ( $5 \mathrm{~min}$ ) to form a dough, portioned, baked $\left(25 \mathrm{~min} ; 200^{\circ} \mathrm{C}\right)$, cooled and stored $\left(-18^{\circ} \mathrm{C}\right)$. Before each test day, the treatments were thawed overnight at room temperature and subsequently served warm on test mornings. DM contents of the treatments were determined by oven-drying $\left(104^{\circ} \mathrm{C} ; 24 \mathrm{~h}\right)$ and samples were freeze-dried (Heto PowerDry PL6000; Thermo Scientific), ball-milled and stored at $-70^{\circ} \mathrm{C}$ until subsequent analysis for betaine and choline concentrations by NMR spectroscopy ${ }^{(22)}$ and for folate concentrations by microbiological assay ${ }^{(23)}$. 
Table 1. Formulation and composition of the treatments

\begin{tabular}{|c|c|c|c|c|c|}
\hline & \multicolumn{3}{|c|}{$\begin{array}{l}\text { Minimally processed } \\
\text { treatments (study A) }\end{array}$} & \multicolumn{2}{|c|}{ Breads (study B) } \\
\hline & Bran & Aleurone & Control & Aleurone & Control \\
\hline \multicolumn{6}{|l|}{ Ingredients (g/portion)* } \\
\hline Wheat bran† & $50 \cdot 0$ & - & - & - & - \\
\hline Wheat aleurone $\dagger$ & - & $50 \cdot 0$ & - & $50 \cdot 0$ & - \\
\hline Wheat fibreł & - & $3 \cdot 6$ & $27 \cdot 0$ & - & $23 \cdot 6$ \\
\hline Wheat protein§ & $2 \cdot 3$ & - & 8.9 & - & 8.81 \\
\hline Wheat starch\| & 0.3 & - & $5 \cdot 6$ & - & 5.63 \\
\hline Vegetable fat $\emptyset$ & 0.6 & - & $2 \cdot 0$ & 14.4 & $16 \cdot 4$ \\
\hline Sugar** & $2 \cdot 5$ & $2 \cdot 5$ & 2.5 & $9 \cdot 2$ & $9 \cdot 2$ \\
\hline White wheat flourt† & - & - & - & $50 \cdot 0$ & $50 \cdot 0$ \\
\hline Buttermilk $\ddagger \ddagger$ & - & - & - & $99 \cdot 0$ & $99 \cdot 0$ \\
\hline Other ingredients ${ }^{\S \S}$ & - & - & - & 2.5 & 2.5 \\
\hline \multicolumn{6}{|l|}{ Composition per portion } \\
\hline Energy (kJ) & 348 & 352 & 336 & 1781 & 1764 \\
\hline Carbohydrate (g) & $8 \cdot 0$ & $8 \cdot 1$ & $7 \cdot 4$ & $53 \cdot 0$ & 52.4 \\
\hline Protein $(\mathrm{g})$ & $8 \cdot 7$ & 8.9 & 8.4 & $18 \cdot 0$ & $17 \cdot 4$ \\
\hline Fat $(\mathrm{g})$ & $2 \cdot 0$ & $2 \cdot 0$ & $2 \cdot 1$ & $17 \cdot 2$ & $17 \cdot 3$ \\
\hline Fibre (g) & 27 & 27 & 25 & 25 & 23 \\
\hline Betaine (mg) & 301 & 515 & 31 & 564 & 86 \\
\hline Choline (mg) & 61 & 71 & 7 & 82 & 23 \\
\hline Folate $(\mu \mathrm{g})$ & 27 & 56 & 6 & 87 & 19 \\
\hline \multicolumn{6}{|c|}{ 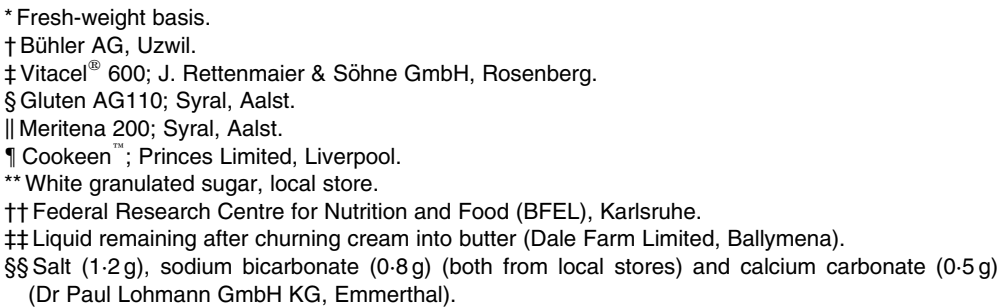 } \\
\hline
\end{tabular}

\section{Blood sampling and analysis}

Blood samples, at baseline and at 0.5, 1, 2 and $3 \mathrm{~h}$ after eating commenced, were taken from an antecubital vein into dipotassium EDTA vacutainers for the analysis of betaine and choline concentrations and into lithium heparin tubes for the analysis of folate concentrations. Plasma was separated by centrifugation $\left(1000 \mathrm{~g}, 15 \mathrm{~min}, 4^{\circ} \mathrm{C}\right)$, aliquoted and stored at $-70^{\circ} \mathrm{C}$ until subsequent batch analysis. Plasma betaine, dimethylglycine (DMG), choline, tHcy and methionine concentrations were determined by liquid chromatographytandem MS/MS at the laboratory of Bevital AS (http://www. bevital.no) ${ }^{(24)}$. Plasma folate concentration was determined by microbiological assay ${ }^{(25)}$.

\section{Statistical analyses}

Statistical analyses were performed using the Statistical Package for the Social Sciences (version 11.5; SPSS, Inc.). Plasma measures were analysed using general linear model repeated-measures ANOVA, and where significant differences were found, post hoc comparisons were made using Bonferroni's test for multiple comparisons for study A and paired $t$ test for study B. Baseline folate and tHcy data deviated from normality and were, thus, logarithmically transformed before statistical analyses. The following pharmacokinetic parameters were derived directly from the data: baselinecorrected peak concentration $\left(C_{\max , \mathrm{corr}}\right)$; time taken to reach peak concentration $\left(t_{\max }\right)$; baseline-corrected AUC $\left(\mathrm{AUC}_{\mathrm{corr}}\right)$ from 0 to $3 \mathrm{~h}$ calculated by the trapezoidal method ${ }^{(26)}$. Differences between baseline measures and between the pharmacokinetic parameters were tested using ANOVA, and post hoc comparisons were made by Bonferroni's test for study A and paired $t$ tests for study B. Independent $t$ tests were used for secondary analyses of sex differences in baseline measures and pharmacokinetic parameters for betaine. Data are presented as means with their standard errors of the mean, and differences were considered significant at $P<0 \cdot 05$.

\section{Results}

\section{Composition of the treatments}

The analyses showed that energy, macronutrient and fibre contents across the minimally processed bran, aleurone and control treatments (study A) and across the aleurone and control breads (study B) were similar (Table 1). However, compared with the control, minimally processed bran was much higher in betaine, choline and folate concentrations, and minimally processed aleurone provided the highest amounts of these components. Furthermore, the aleurone bread was substantially higher in betaine, choline and folate concentrations than the control bread. Both minimally processed aleurone and the aleurone bread contained almost twice as much betaine as wheat bran (Table 1). In the minimally processed treatments, folate content was higher in aleurone than in 
wheat bran, while choline was found at similar concentrations in both wheat aleurone and wheat bran.

\section{Completion and compliance}

Study A was completed by all the participants (seven males; seven females; age 27.8 (SEM 1.7) years; BMI 22.7 (SEM $0 \cdot 7) \mathrm{kg} / \mathrm{m}^{2}$ ), and there were no significant differences in compliance $(P=0 \cdot 21$ ), which was 93.4 (SEM $4 \cdot 1$ ), 96.1 (SEM $1 \cdot 8$ ) and $100 \%$ for bran, aleurone and control, respectively. However, one male participant withdrew from study B for personal reasons unrelated to the study (data not included); thus, statistical analyses were performed on thirteen participants (six males; seven females; age 33.9 (SEM 1.7) years; BMI $\left.25 \cdot 0(\operatorname{sem~} 1 \cdot 0) \mathrm{kg} / \mathrm{m}^{2}\right)$. In study $\mathrm{B}$, there were no significant differences in compliance $(P=0 \cdot 10)$, which was $96 \cdot 1$ (SEm 2.3) and $100.0 \%$ for the aleurone and control breads, respectively.

\section{Plasma responses in study A (minimally processed treatments)}

Compared with baseline, plasma betaine concentrations were significantly increased at all time points $(0.5,1,2$ and $3 \mathrm{~h}$; $P<0.001)$ following the consumption of both bran and aleurone; however, no significant changes were observed following
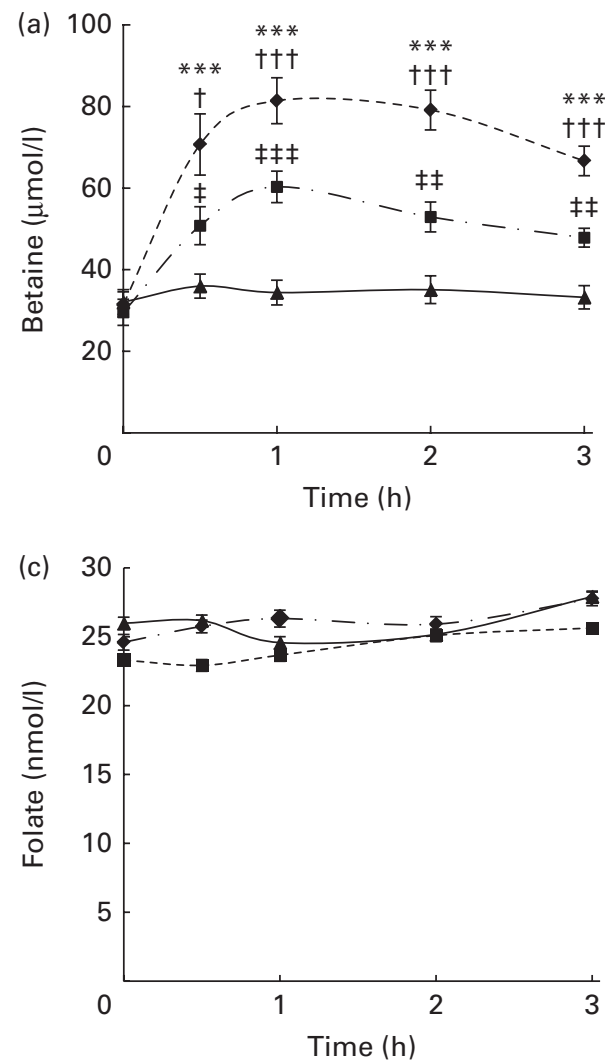

consumption of the control (Fig. 1(a)). Compared with the control, plasma betaine concentrations were significantly higher following the consumption of bran and aleurone from the first sampling $(0.5 \mathrm{~h})$ to the last sampling $(3 \mathrm{~h})$, when plasma betaine concentrations remained significantly above baseline for both fractions (Fig. 1(a)). Furthermore, plasma betaine concentrations were significantly higher following the consumption of aleurone compared with bran from $0.5 \mathrm{~h}$ to $3 \mathrm{~h}$. The pharmacokinetic data reflected these results: the $C_{\text {max, corr }}$ and $\mathrm{AUC}_{\text {corr }}$ values for plasma betaine concentrations were significantly higher following the consumption of bran and aleurone compared with the control (Table 2). In addition, the $C_{\max \text {, corr }}$ and $\mathrm{AUC}_{\mathrm{corr}}$ values for aleurone were significantly and substantially higher than those for bran (Table 2). The values of $C_{\max \text {, corr }}$ for plasma betaine concentrations were 1.1 and 1.8 times the baseline levels, and the $t_{\max }$ values for bran and aleurone were 1.0 and $1.2 \mathrm{~h}$, respectively. The secondary analyses showed that mean baseline plasma betaine concentrations were higher in males than in females $(37.9 v .24 .2 \mu \mathrm{mol} / \mathrm{l} ; P<0.001)$. However, no significant differences were observed between males and females for values of the baseline-corrected area under the treatment effect curve (62.8 (SEM 7.6) $v$. 65.9 (SEM 9.3) $\mu \mathrm{mol} / 1$ per h; $P=0.80$ and 123.2 (SEM 6.9) $v .116 .5$ (SEM 14.9) $\mu \mathrm{mol} / \mathrm{l}$ per h; $P=0.69$ ) following the consumption of bran and aleurone, respectively.
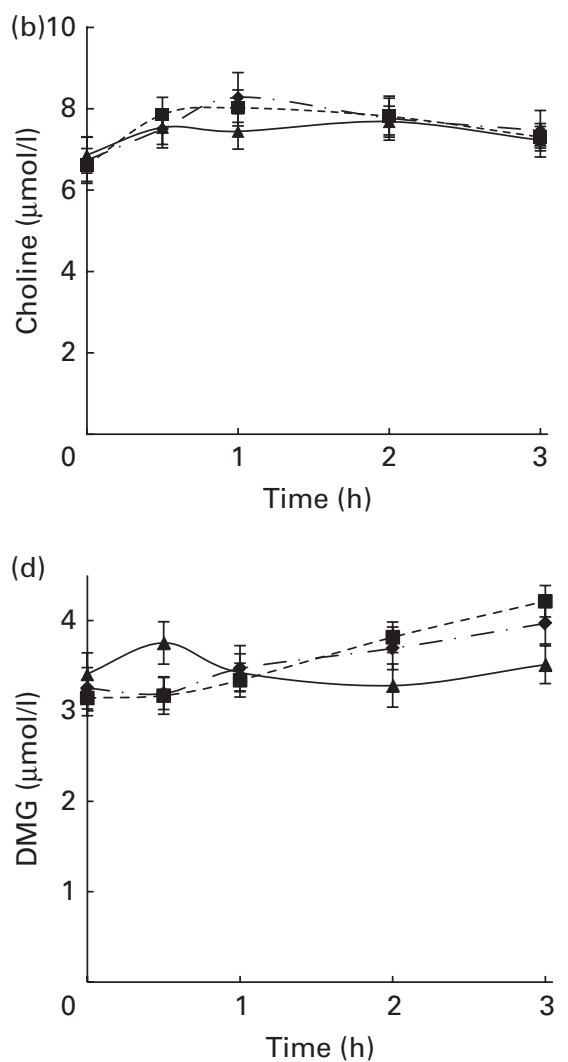

Fig. 1. Plasma concentrations of (a) betaine, (b) choline, (c) folate and (d) dimethylglycine (DMG) after consumption of minimally processed fractions. Values are means, with their standard errors represented by vertical bars $(n 13)$. ${ }^{\star \star \star}$ Mean value for aleurone $(\star)$ was significantly different from that for control $(\boldsymbol{\Lambda})$ $(P<0.001)$. Mean value for aleurone was significantly different from that for wheat bran $(\square)$ : $\dagger P<0.05, \dagger \dagger \dagger P<0.001$. Mean value for wheat bran was significantly different from that for control: $\ddagger P<0.05, \ddagger \ddagger P<0.01, \ddagger \ddagger \ddagger P<0.001$. 
Table 2. Pharmacokinetic data after consumption of the treatments

(Mean values with their standard errors)

\begin{tabular}{|c|c|c|c|c|c|c|c|c|c|c|c|c|}
\hline & \multicolumn{7}{|c|}{ Minimally processed treatments (study A) } & \multicolumn{5}{|c|}{ Breads (study B) } \\
\hline & \multicolumn{2}{|c|}{ Bran } & \multicolumn{2}{|c|}{ Aleurone } & \multicolumn{2}{|c|}{ Control } & \multirow[b]{2}{*}{$P^{*}$} & \multicolumn{2}{|c|}{ Aleurone } & \multicolumn{2}{|c|}{ Control } & \multirow[b]{2}{*}{$P \dagger$} \\
\hline & Mean & SEM & Mean & SEM & Mean & SEM & & Mean & SEM & Mean & SEM & \\
\hline \multicolumn{13}{|l|}{ Plasma betaine } \\
\hline Baseline $(\mu \mathrm{mol} / \mathrm{l})$ & 29.6 & 3.2 & 31.5 & $3 \cdot 1$ & $32 \cdot 1$ & 3.0 & 0.84 & $35 \cdot 5$ & $2 \cdot 2$ & $34 \cdot 2$ & $2 \cdot 0$ & 0.26 \\
\hline$C_{\max , \text { corr }}(\mu \mathrm{mol} / \mathrm{l})$ & $32 \cdot 8^{a}$ & $2 \cdot 7$ & $56 \cdot 5^{\mathrm{b}}$ & $3 \cdot 3$ & $6 \cdot 5^{c}$ & 0.8 & $<0.001$ & $60 \cdot 4^{\mathrm{a}}$ & 3.7 & $6 \cdot 1^{b}$ & 1.5 & $<0.001$ \\
\hline $\mathrm{AUC}_{\mathrm{corr}}(\mu \mathrm{mol} / /$ per $\mathrm{h})$ & $64 \cdot 4^{\mathrm{a}}$ & $5 \cdot 8$ & $119 \cdot 9^{b}$ & 8.0 & $8 \cdot 1^{\mathrm{c}}$ & 1.8 & $<0.001$ & $115 \cdot 5^{\mathrm{a}}$ & $7 \cdot 3$ & $8 \cdot 8^{\mathrm{b}}$ & 2.5 & $<0.001$ \\
\hline \multicolumn{13}{|l|}{ Plasma choline } \\
\hline Baseline $(\mu \mathrm{mol} / \mathrm{l})$ & $6 \cdot 7$ & 0.6 & $6 \cdot 6$ & 0.4 & $6 \cdot 9$ & 0.5 & 0.93 & 8.5 & 0.5 & $7 \cdot 8$ & 0.5 & 0.13 \\
\hline$C_{\max , \text { corr }}(\mu \mathrm{mol} / /)$ & $2 \cdot 2$ & 0.3 & $2 \cdot 7$ & 0.5 & $2 \cdot 2$ & 0.3 & 0.52 & $2 \cdot 0$ & 0.2 & 1.5 & 0.2 & 0.07 \\
\hline$A \cup C_{\text {corr }}(\mu \mathrm{mol} / \mathrm{h})$ & 3.7 & 0.6 & $5 \cdot 2$ & $1 \cdot 1$ & 3.3 & 0.7 & 0.27 & 3.4 & 0.4 & $2 \cdot 3$ & 0.6 & $0 \cdot 10$ \\
\hline \multicolumn{13}{|l|}{ Plasma folate } \\
\hline Baseline (nmol/l) & $24 \cdot 6$ & 4.2 & $23 \cdot 3$ & 3.0 & $26 \cdot 0$ & 4.4 & 0.89 & 28.5 & 3.8 & $27 \cdot 4$ & $2 \cdot 7$ & 0.72 \\
\hline$C_{\max , \text { corr }}(\mathrm{nmol} / \mathrm{l})$ & 4.5 & 0.9 & $4 \cdot 8$ & $1 \cdot 2$ & 3.9 & 0.6 & 0.85 & $4 \cdot 7^{\mathrm{a}}$ & 0.4 & $1.0^{\mathrm{b}}$ & 0.0 & $<0.01$ \\
\hline $\mathrm{AUC}_{\text {corr }}(\mathrm{nmol} / \mathrm{l}$ per h) & $6 \cdot 7$ & 1.5 & $7 \cdot 7$ & $2 \cdot 2$ & $4 \cdot 1$ & 0.9 & 0.38 & $7 \cdot 9^{a}$ & 0.9 & $1 \cdot 7^{\mathrm{b}}$ & 0.6 & $<0.05$ \\
\hline \multicolumn{13}{|l|}{ Plasma DMG } \\
\hline Baseline $(\mu \mathrm{mol} / \mathrm{l})$ & 3.3 & 0.2 & $3 \cdot 1$ & 0.2 & 3.4 & 0.2 & 0.69 & 3.1 & 0.2 & 2.9 & 0.2 & 0.43 \\
\hline$C_{\max , \text { corr }}(\mu \mathrm{mol} / \mathrm{l})$ & $0.8^{\mathrm{a}}$ & 0.1 & $1 \cdot 1^{b}$ & 0.1 & $0.6^{\mathrm{c}}$ & 0.1 & $<0.01$ & $1 \cdot 0^{\mathrm{a}}$ & 0.1 & $0.5^{\mathrm{b}}$ & 0.2 & $<0.05$ \\
\hline $\mathrm{AUC}_{\text {corr }}(\mu \mathrm{mol} / \mathrm{l}$ per $\mathrm{h})$ & $1 \cdot 0$ & 0.2 & 1.4 & 0.3 & 0.8 & 0.3 & 0.25 & $1 \cdot 5^{\mathrm{a}}$ & 0.2 & $0.4^{\mathrm{b}}$ & 0.1 & $<0.01$ \\
\hline
\end{tabular}

$C_{\text {max, corr }}$, baseline-corrected peak concentration; $\mathrm{AUC}_{\text {corr }}$, baseline-corrected area under the postprandial concentration-time curve; DMG, dimethylglycine.

a,b,c For each study, mean values within a row with unlike superscript letters were significantly different $(P<0.05)$.

${ }^{*} P$ values were obtained by ANOVA.

$\dagger P$ values were obtained by $t$ test.

Compared with the control, no significant changes were observed in the plasma concentrations of choline, folate or DMG following the consumption of bran and aleurone (Fig. 1(b)-(d)). However, plasma DMG concentrations showed non-significant increases up to the last sampling $(3 \mathrm{~h})$ following the consumption of both aleurone and bran, and this was more pronounced for aleurone (Fig. 1(d)). These differences were reflected in the pharmacokinetic data: the $C_{\max \text {, corr }}$ value for plasma DMG concentrations following the consumption of aleurone and bran was significantly higher than that of the control, and the $C_{\max \text {, corr }}$ value following the consumption of aleurone was significantly higher than that after consumption of bran (Table 2). No significant effects of treatment on the plasma concentration of tHcy $(P=0.96)$ or methionine $(P=0.97)$ were observed (data not shown).

\section{Plasma responses in study $B$ (breads)}

Compared with baseline and the control bread, plasma betaine concentrations following consumption of the aleurone bread were significantly $(P<0 \cdot 001)$ higher from the first sampling at $0.5 \mathrm{~h}$ through to the last sampling $(3 \mathrm{~h})$, when plasma betaine concentrations were still substantially elevated (Fig. 2(a)). These effects were reflected in the pharmacokinetic data: the $C_{\max \text {, corr }}$ and $\mathrm{AUC}_{\text {corr }}$ values for plasma betaine concentrations were significantly and substantially higher following consumption of the aleurone bread, compared with the control bread (Table 2). The value of $C_{\max \text {, corr }}$ for plasma betaine concentrations was 1.7 times the baseline levels (Table 2), with the $t_{\max }$ value being $2 \cdot 1 \mathrm{~h}$. As in study A, the secondary analyses showed that baseline plasma betaine concentrations were higher in males than in females (38.3 v. $32.7 \mu \mathrm{mol} / 1 ; P=0.017)$; however, no significant differences were observed between males and females for values of the baseline-corrected area under the treatment effect curve (123.1 (SEM 12.1) v. 109.0 (sEM 8.9) $\mu \mathrm{mol} / 1$ per h; $P=0 \cdot 83$ ).

Compared with the control bread, plasma choline concentrations were higher following consumption of the aleurone bread, and the effect of treatment approached significance $(P=0.058$; Fig. 2(b)). However, no significant differences from baseline or between the treatments in plasma choline concentrations were observed. Furthermore, no significant differences between the $C_{\max \text {, corr }}$ and $\mathrm{AUC}_{\text {corr }}$ values for plasma choline concentrations were observed, although both pharmacokinetic responses were higher for the aleurone bread than for the control bread, and the differences approached significance $(P=0.07$ and $P=0 \cdot 10$, respectively; Table 2). Overall, no significant effects of treatment on plasma folate concentrations $(P=0.89$; Fig. 2(c) $)$ were observed; however, both $C_{\max , \text { corr }}$ and $\mathrm{AUC}_{\text {corr }}$ values were significantly higher for the aleurone bread than for the control bread; however, these differences were small (Table 2).

The effect of treatment did not reach significance $(P=0.084)$ for plasma DMG concentrations. However, plasma DMG concentrations following consumption of the aleurone bread showed non-significant increases with sampling time compared with the control bread (Fig. 2(d)). Furthermore, although the differences were relatively small, the $C_{\max , \text { corr }}$ and $\mathrm{AUC}_{\text {corr }}$ values were significantly higher for plasma DMG concentrations following consumption of the aleurone bread compared with the control bread (Table 2). No significant effects of treatment on the plasma concentration of tHcy $(P=0.58)$ or methionine $(P=0 \cdot 94)$ were observed (data not shown).

\section{Discussion}

The present results show that consumption of $50 \mathrm{~g}$ portions of minimally processed wheat bran led to substantial postpran- 

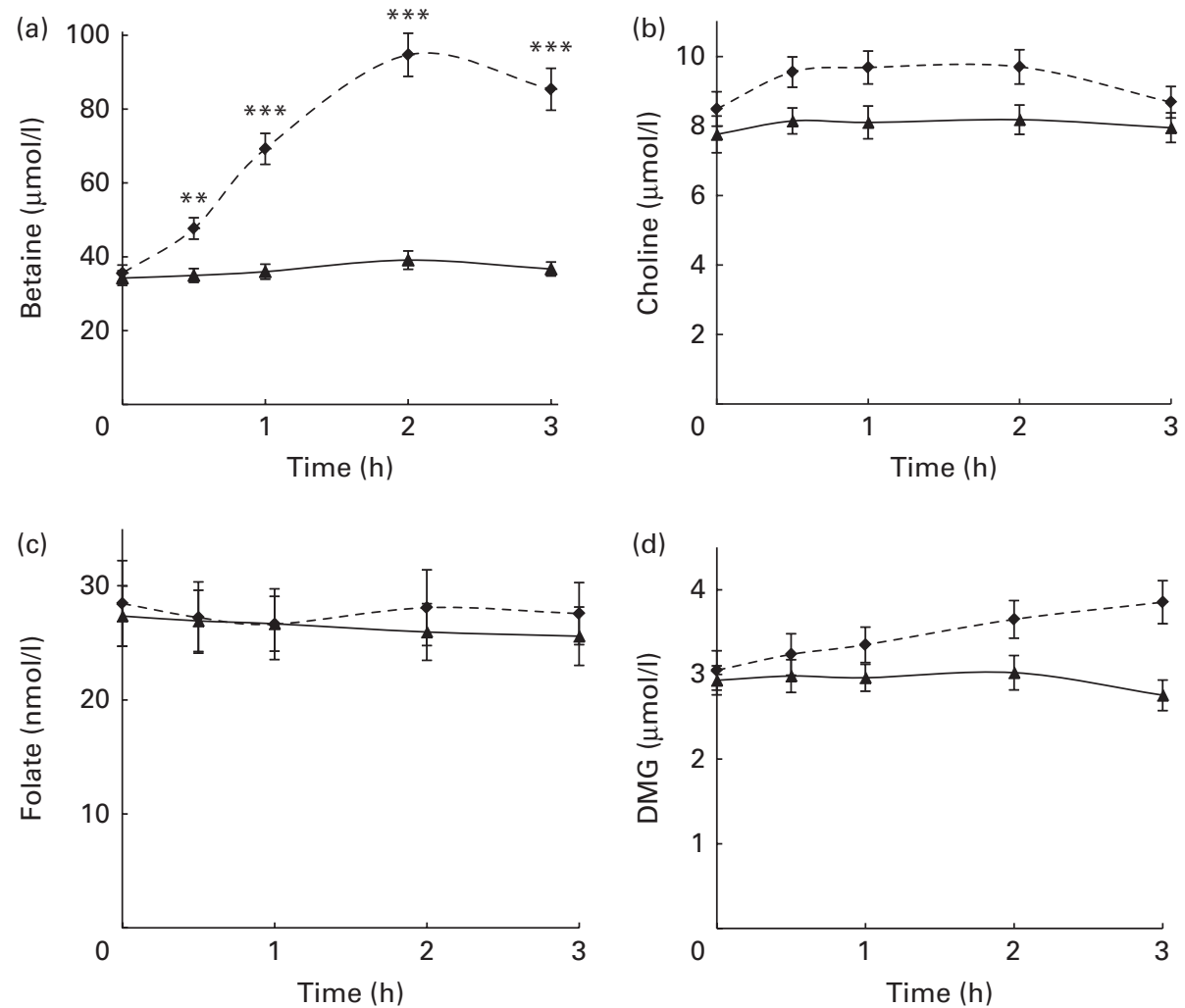

Fig. 2. Plasma concentrations of (a) betaine, (b) choline, (c) folate and (d) dimethylglycine (DMG) after consumption of breads. Values are means, with their standard errors represented by vertical bars $(n 13)$. ${ }^{*}$ Mean value for aleurone $(\bullet)$ was significantly different from that for control $(\mathbf{\Lambda}):{ }^{* *} P<0.01,{ }^{* * *} P<0.001$.

dial increases in plasma betaine concentrations. Furthermore, consumption of minimally processed wheat aleurone increased plasma betaine concentrations to a greater extent than wheat bran, and the increase in plasma betaine concentrations was similar to that when the same amount of wheat aleurone was incorporated into bread. However, other plasma methyl donor-related responses were generally small and non-significant.

As may be expected for a water-soluble component, plasma betaine concentrations increased relatively rapidly following ingestion, and the $t_{\max }$ values for plasma betaine concentrations were $1 \cdot 0,1 \cdot 2$ and $2 \cdot 1 \mathrm{~h}$ following the consumption of minimally processed bran, minimally processed aleurone and aleurone bread, respectively. Previous results, obtained following consumption of a meal composed of extruded wheat bran cereal, wheat bran and whole-grain toast and which had a very similar betaine content $(560 \mathrm{mg})$ to both the minimally processed aleurone and the aleurone bread used here ( 515 and $564 \mathrm{mg}$, respectively), have shown peak plasma betaine concentrations at $2.6 \mathrm{~h}$, in contrast to $1.8 \mathrm{~h}$ following consumption of a $500 \mathrm{mg}$ betaine supplement ${ }^{(21)}$. Furthermore, with consumption of betaine supplements ranging from 1 to $6 \mathrm{~g}$, the $t_{\max }$ value for plasma betaine concentrations ranged between 0.7 and $1 \cdot 3 \mathrm{~h}^{(26,27)}$. Overall, these results indicate that processing of bran fractions into more complex food matrices by baking or by extrusion reduces the release and absorption rates of betaine.

Previous results with consumption of betaine supplements have shown that the $C_{\max \text {, corr }}$ values for plasma betaine concentrations increased from 239 to $966 \mu \mathrm{mol} / 1$ when betaine doses increased from 1 to $6 \mathrm{~g}^{(26)}$. Dose-dependent increases in the $C_{\max , \text { corr }}$ values $(33,57$ and $60 \mu \mathrm{mol} / \mathrm{l})$ were also found in the two present studies (study A and study B) in which betaine intakes were much lower (minimally processed bran, $301 \mathrm{mg}$; minimally processed aleurone, $515 \mathrm{mg}$; aleurone bread, $564 \mathrm{mg}$ ). Furthermore, in the two studies, the $C_{\max \text {, corr }}$ values were similar to those found by Atkinson et al. ${ }^{(21)}$ following consumption of a meal composed of bran cereal, wheat bran and whole-grain toast $(39 \mu \mathrm{mol} / \mathrm{l})$.

The results of the two studies suggested that there may be little difference in the effects of minimally processed aleurone or aleurone incorporated into bread on plasma betaine responses, as the values of $C_{\max , \text { corr }}$ and $\mathrm{AUC}_{\mathrm{corr}}$ for plasma betaine concentrations were similar. However, the results of the two studies were not directly comparable. In both studies, plasma betaine concentrations remained significantly and substantially elevated up to the last sampling time $(3 \mathrm{~h})$. The results from the study by Atkinson et al. ${ }^{(21)}$ with a meal containing similar levels of betaine to those used here indicated that plasma betaine concentrations may remain significantly elevated until $8 \mathrm{~h}$; thus, it may be useful to extend sampling times in future studies. It is important to note that plasma betaine concentrations reflect the balance between absorption, metabolism to DMG, synthesis from choline, storage and elimination. There are no extant data on the rate at which betaine is metabolised or relocated to other tissues; however, betaine is present at much higher concentrations in muscle, liver and kidney tissues than in plasma ${ }^{(28)}$, and 
urinary postprandial excretion is limited ${ }^{(26)}$. Thus, uptake of betaine is likely to be higher than indicated by plasma measurements. In a study by Schwahn et al. ${ }^{(27)}$, consumption of betaine supplements $(3-5 \mathrm{~g})$ led to small, but significant, increases at $3 \mathrm{~h}$ in the plasma concentrations of the betaine metabolite, DMG, which reached a maximum at $9 \mathrm{~h}$. However, the small increases observed in plasma DMG concentrations in both studies (study A and study B) suggested that metabolism of betaine may occur relatively rapidly after uptake.

Plasma choline concentrations did not show significant changes following the consumption of minimally processed bran or aleurone. Nevertheless, very small changes were observed following consumption of the aleurone bread, which approached significance. There are no previous reports on the effects of dietary choline intake from cereal sources on plasma choline concentrations. It is noteworthy that the amount of choline provided by the treatments in both studies was relatively low compared with rich dietary sources, such as eggs ${ }^{(29)}$.

There were no significant effects of treatment on plasma folate concentrations in either study; however, consumption of the aleurone bread led to small, but significant, increases in the values of $C_{\max \text {, corr }}$ and $\mathrm{AUC}_{\mathrm{corr}}$ for plasma folate concentrations. In a previous postprandial study carried out in Australia, plasma folate concentrations have been found to be significantly increased following consumption of $100 \mathrm{~g}$ cereal made from an aleurone flour ${ }^{(2)}$; however, the amount of folate in the cereal in that study $(515 \mu \mathrm{g} /$ portion) was much higher than that in the minimally processed aleurone or the aleurone bread (56 and $87 \mu \mathrm{g}$ /portion, respectively) in the present studies. The reasons for the substantially higher folate content of aleurone in the Australian study are unclear; however, it may be due to variations in genotype and growing conditions ${ }^{(30)}$.

Significant decreases in plasma tHcy concentrations, which persisted for at least $7 \mathrm{~h}$, have been reported following the consumption of betaine supplements of 3 or $6 \mathrm{~g}$, but not $1 \mathrm{~g}^{(26)}$. However, Atkinson et $a l^{(21)}$ have found small, but significant, decreases in plasma tHcy concentrations at $6 \mathrm{~h}$ following consumption of a meal containing about $560 \mathrm{mg}$ betaine, but not following consumption of a $500 \mathrm{mg}$ betaine supplement. Overall, these reports suggest that the lack of significant changes in plasma tHcy or methionine concentrations in both studies could be due to the lower amounts of betaine provided (301-564 mg), combined with the relatively short duration of sampling $(3 \mathrm{~h})$.

In contrast, the results from three longer-term interventions $^{(19,20,31)}$ have shown that diets rich in aleurone or whole grains led to increased fasting plasma betaine concentrations, which, in two studies, was associated with decreased plasma tHcy concentrations ${ }^{(19,20)}$. In the first of these interventions, consumption of the aleurone bread $(38.5 \mathrm{~g}$ aleurone/d) for $>8$ weeks significantly lowered plasma tHcy concentrations to a similar degree to that found with consumption of a folic acid supplement $(500 \mathrm{mg})^{(31)}$. However, these authors have attributed the decreased tHcy concentration to the high folate content of the aleurone bread ${ }^{(31)}$; however, betaine and choline concentrations present in aleurone may also have contributed to the decrease. The second study was a 4-week intervention by our group using aleurone-rich foods that provided $27 \mathrm{~g}$ aleurone/d (containing $279 \mathrm{mg}$ betaine/d), which resulted in significant increases in plasma betaine concentrations and decreases in plasma tHcy concentrations that were attributed to the increased dietary betaine intake $^{(19)}$. The third study was a 2 -week intervention with whole-grain cereals (providing $119 \mathrm{mg}$ betaine/d), which resulted in significant increases in plasma betaine concentrations; however, plasma tHcy concentration was not affected $^{(20)}$. Overall, despite the variations in duration, these longer-term studies have suggested that aleurone, which is rich in betaine and other bioactive components, may be effective at ameliorating biomarkers such as tHcy.

In order to maximise any potential postprandial responses, the amount of bran and aleurone fractions used in these studies was relatively large $(50 \mathrm{~g})$, and some of the treatments may have had low palatability. However, in the two previous longer-term intervention studies outlined above ${ }^{(19,31)}$, aleurone was successfully included in diets at $38.5 \mathrm{~g} / \mathrm{d}$ for 16 weeks $^{(31)}$ and at $27 \mathrm{~g} / \mathrm{d}$ for 4 weeks, by incorporation into breads and ready-to-eat cereals ${ }^{(19)}$. Thus, bran and aleurone, which contain about 600 and $1000 \mathrm{mg}$ betaine/ $100 \mathrm{~g}$, respectively (Table 1), could be used as ingredients in the production of consumer foods whose consumption may substantially increase current habitual betaine intakes $(100-314 \mathrm{mg} / \mathrm{d})^{(19,32,33)}$. Betaine insufficiency has been associated with the metabolic syndrome ${ }^{(34)}$, lipid disorders ${ }^{(35)}$, vascular disease ${ }^{(36)}$, age-related macular disease ${ }^{(37)}$, cognitive decline $e^{(38)}$ and colorectal cancer risk ${ }^{(39)}$; thus, such foods could potentially offer a number of beneficial health effects.

In conclusion, these results showed that consumption of minimally processed wheat bran, and in particular wheat aleurone, yielded substantial postprandial increases in plasma betaine concentrations. Furthermore, these effects appear to be maintained when aleurone was incorporated into bread.

\section{Acknowledgements}

The present study was financially supported by the European Commission in the Communities 6th Framework Programme Project, HEALTHGRAIN (FP6-514008). This publication reflects only views of the authors and the Community is not liable for any use that may be made of the information contained in this publication. The European Commission had no role in the design and analysis of the study or in the writing of this article. Rothamsted Research receives strategic funding from the Biotechnological and Biological Sciences Research Council (BBSRC). Bühler AG, Uzwil, Switzerland, provided bran and aleurone fractions and associated data.

The contributions of the authors are as follows: E. M. K., L. L. H., R. K. P., J. M. W. W. and R. W. W. designed the research with advice from H. M., M. W. and J. J. S.; L. L. H., E. M. K. and R. K. P. conducted the trials; W. v. R. supplied the wheat fractions and associated proximate analysis data; V. P. performed the folate analyses of the foods; P. R. S. and J. L. W. performed the betaine and choline analyses of the foods; A. M. M. performed the plasma folate analyses; 
P. M. U. performed the analyses of plasma betaine and other methyl donor-related metabolites; L. L. H., E. M. K., R. K. P., J. M. W. W. and R. W. W. analysed the data; E. M. K., R. K. P., J. M. W. W. and R. W. W. wrote the manuscript. All authors contributed to the interpretation of the data and critically revised the final manuscript. Preliminary reports of parts of study A were given at Nutrition Society meetings at Coleraine, UK, July $2007^{(40)}$, and Dublin, Republic of Ireland, June $2008^{(41)}$.

W. V. R. is working for Bühler AG, Uzwil, Switzerland; Bühler provides services and equipments for food processing. All the other authors declare that there is no conflict of interest.

\section{References}

1. Buri RC, von Reding W \& Gavin MH (2004) Description and characterization of wheat aleurone. Cereal Foods World 49 , 274-282.

2. Fenech M, Noakes M, Clifton P, et al. (1999) Aleurone flour is a rich source of bioavailable folate in humans. J Nutr $\mathbf{1 2 9}$, $1114-1119$.

3. Likes R, Madl RL, Zeisel SH, et al. (2007) The betaine and choline content of a whole wheat flour compared to other mill streams. J Cereal Sci 46, 93-95.

4. Graham SF, Hollis JH, Migaud M, et al. (2009) Analysis of betaine and choline contents of aleurone, bran, and flour fractions of wheat (Triticum aestivum L.) using H-1 Nuclear Magnetic Resonance (NMR) spectroscopy. J Agric Food Chem 57, 1948-1951.

5. Kamal-Eldin A, Laerke HN, Knudsen K-EB, et al. (2009) Physical, microscopic and chemical characterisation of industrial rye and wheat brans from the Nordic countries. Food Nutr Res (epublication 22 April 2009).

6. Brouns F, Hemery Y, Price R, et al. (2012) Wheat aleurone: separation, composition, health aspects, and potential food use. Crit Rev Food Sci Nutr 52, 553-568.

7. Niculescu MD \& Zeisel SH (2002) Diet, methyl donors and DNA methylation: interactions between dietary folate, methionine and choline. J Nutr 132, 2333S-2335S.

8. Zeisel SH \& Blusztajn JK (1994) Choline and human nutrition. Annu Rev Nutr 14, 269-296.

9. Ueland PM, Holm PI \& Hustad S (2005) Betaine: a key modulator of one-carbon metabolism and homocysteine status. Clin Chem Lab Med 43, 1069-1075.

10. Craig SAS (2004) Betaine in human nutrition. Am J Clin Nutr 80, 539-549.

11. Scott J \& Weir D (1994) Folate/vitamin B-12 inter-relationships. Essays Biochem 28, 63-72.

12. Kelly SAM, Summerbell CD, Brynes A, et al. (2007) Wholegrain cereals for coronary heart disease. Cochrane Database Syst Rev, Issue 2, CD005051.

13. Schatzkin A, Mouw T, Park Y, et al. (2007) Dietary fiber and whole-grain consumption in relation to colorectal cancer in the NIH-AARP Diet and Health Study. Am J Clin Nutr 85, $1353-1360$.

14. Sahyoun NR, Jacques PF, Zhang XL, et al. (2006) Wholegrain intake is inversely associated with the metabolic syndrome and mortality in older adults. Am J Clin Nutr $\mathbf{8 3}$, 124-131.

15. Jensen MK, Koh-Banerjee P, Hu FB, et al. (2004) Intakes of whole grains, bran, and germ and the risk of coronary heart disease in men. Am J Clin Nutr 80, 1492-1499.
16. Liu SM, Stampfer MJ, Hu FB, et al. (1999) Whole-grain consumption and risk of coronary heart disease: results from the Nurses' Health Study. Am J Clin Nutr 70, $412-419$.

17. Fardet A (2010) New hypotheses for the health-protective mechanisms of whole-grain cereals: what is beyond fibre? Nutr Res Rev 23, 65-134.

18. Seal CJ \& Brownlee IA (2010) Whole grains and health, evidence from observational and intervention studies. Cereal Chem 87, 167-174.

19. Price RK, Keaveney EM, Hamill LL, et al. (2010) Consumption of wheat aleurone-rich foods increases fasting plasma betaine and modestly decreases fasting homocysteine and LDL-cholesterol in adults. J Nutr 140, 2153-2157.

20. Ross $\mathrm{AB} \&$ \& Bruce SJ (2011) A whole-grain cereal-rich diet increases plasma betaine, and tends to decrease total and LDL-cholesterol compared with a refined-grain diet in healthy subjects. Br J Nutr 105, 1492-1502.

21. Atkinson W, Elmslie J, Lever M, et al. (2008) Dietary and supplementary betaine: acute effects on plasma betaine and homocysteine concentrations under standard and postmethionine load conditions in healthy male subjects. Am J Clin Nutr 87, 577-585.

22. Corol DI, Ravel C, Raksegi M, et al. (2012) Effects of genotype and environment on the contents of betaine, choline, and trigonelline in cereal grains. J Agric Food Chem 60, 5471-5481.

23. Piironen V, Edelmann M, Kariluoto S, et al. (2008) Folate in wheat genotypes in the HEALTHGRAIN diversity screen. J Agr Food Chem 56, 9726-9731.

24. Midttun $\varnothing$, Kvalheim G \& Ueland PM (2013) High-throughput, low-volume, multianalyte quantification of plasma metabolites related to one-carbon metabolism using HPLCMS/MS. Anal Bioanal Chem 405, 2009-2017.

25. Molloy AM \& Scott JM (1997) Microbiological assay for serum, plasma, and red cell folate using cryopreserved, microtiter plate method. Method Enzymol 281, 43-53.

26. Schwab U, Torronen A, Meririnne E, et al. (2006) Orally administered betaine has an acute and dose-dependent effect on serum betaine and plasma homocysteine concentrations in healthy humans. J Nutr 136, 34-38.

27. Schwahn BC, Hafner D, Hohlfeld T, et al. (2003) Pharmacokinetics of oral betaine in healthy subjects and patients with homocystinuria. Br J Clin Pharmacol 55, 6-13.

28. Slow S, Lever M, Chambers ST, et al. (2009) Plasma dependent and independent accumulation of betaine in male and female rat tissues. Physiol Res 58, 403-410.

29. Patterson KY, Bhagwat SA \& Williams JR, et al., (2008) USDA Database for the Choline Content of Common Foods Release 2. http://www.ars.usda.gov/SP2UserFiles/Place/123 54500/Data/Choline/Choln02.pdf (accessed April 2014)

30. Kariluoto S, Edelmann M \& Piironen V (2010) Effects of environment and genotype on folate contents in wheat in the HEALTHGRAIN diversity screen. J Agr Food Chem $\mathbf{5 8}$, 9324-9331.

31. Fenech M, Noakes M, Clifton P, et al. (2005) Aleurone flour increases red-cell folate and lowers plasma homocyst(e)ine substantially in man. Br J Nutr 93, 353-360.

32. Bidulescu A, Chambless LE, Siega-Riz AM, et al. (2009) Repeatability and measurement error in the assessment of choline and betaine dietary intake: the Atherosclerosis Risk in Communities (ARIC) Study. Nutr J 8, 14.

33. Detopoulou $\mathrm{P}$, Panagiotakos $\mathrm{DB}$, Antonopoulou $\mathrm{S}$, et al. (2008) Dietary choline and betaine intakes in relation to concentrations of inflammatory markers in healthy adults: the ATTICA study. Am J Clin Nutr 87, 424-430. 
34. Konstantinova SV, Tell GS, Vollset SE, et al. (2008) Divergent associations of plasma choline and betaine with components of metabolic syndrome in middle age and elderly men and women. J Nutr 138, 914-920.

35. Lever M, George PM, Dellow WJ, et al. (2005) Homocysteine, glycine betaine, and N,N-dimethylglycine in patients attending a lipid clinic. Metabolism 54, 1-14.

36. Alfthan G, Tapani K, Nissinen K, et al. (2004) The effect of low doses of betaine on plasma homocysteine in healthy volunteers. Br J Nutr 92, 665-669.

37. Seddon JM, Reynolds R, Shah HR, et al. (2011) Smoking, dietary betaine, methionine, and vitamin $\mathrm{D}$ in monozygotic twins with discordant macular degeneration: epigenetic implications. Ophthalmology 118, 1386-1394.
38. Eussen SJPM, Ueland PM, Clarke R, et al. (2007) The association of betaine, homocysteine and related metabolites with cognitive function in Dutch elderly people. BrJ Nutr 98, 960-968.

39. Nitter M, Norgård B, de Vogel S, et al. (2014) Plasma methionine, choline, betaine, and dimethylglycine in relation to colorectal cancer risk in the European Prospective Investigation into Cancer and Nutrition (EPIC). Ann Oncol 25, 1609-1615.

40. Price RK, Keaveney EM, Hamill LL, et al. (2007) Plasma uptake of methyl donors from wheat fractions by human subjects. Proc Nutr Soc 66, 114A.

41. Keaveney EM, Hamill LL, Price RK, et al. (2009) Evaluation of the uptake of bioactive components from wheat-bran and wheat-aleurone fractions in healthy adults. Proc Nutr Soc 67, OCE7, E244. 